20 Elwood PC, Cochrane AL, Burr ML, Sweetnam PM, Williams G, Welsby E, $e t$ al. A randomised controlled trial of acetylsalicylic acid in the secondary prevention of mortality from myocardial infarction. BMF 1974;i:436-40.

21 Pritchard PJ, Kitchingman GK, Walt RP, Daneshmend TK, Hawkey CJ. Human gastric mucosal bleeding induced by low dose aspirin but not warfarin. $B M \mathcal{F} 1989 ; 298: 493-6$.

22 Petersen P, Boysen G, Godtfredsen J, Andersen ED, Andersen B. Placebocontrolled, randomised trial of warfarin and aspirin for prevention of thromboembolic complications in chronic atrial fibrillation. Lancet 1989;i: $175-9$.

23 Meade TW, Roderick PJ, Brennan PJ, Wilkes HC, Kelleher CC. Extra-cranial bleeding and other symptoms due to low dose aspirin and low intensity oral anticoagulation. Thromb Haemost 1992;68:1-6.

24 SALT Collaborative Group. Swedish aspirin low-dose trial (SALT) of $75 \mathrm{mg}$ aspirin as secondary prophylaxis after cerebrovascular ischaemic events. Lancet 1991;338:1345-9.

25 RISC Group. Risk of myocardial infarction and death during treatment with low-dose aspirin and intravenous heparin in men with unstable coronary artery disease. Lancet 1990;336:827-30.
26 Dutch TIA Trial Study Group. A comparison of two doses of aspirin $(30 \mathrm{mg}$ vs $283 \mathrm{mg}$ a day) in patients after a transient ischemic attack or minor ischemic stroke. N Engl Y Med 1991;325:1261-6.

27 Roderick PJ, Wilkes HC, Meade TW. The gastrointestinal toxicity of aspirin: an overview of randomised controlled trials. $\mathrm{Br}$ f Clin Pharmacol 1993;35: 219-26.

28 Shorrock CJ, Langman MJS, Warlow CJ. Risks of upper GI bleeding during TIA prophylaxis with aspirin. Gastroenterology 1992;102:A165.

29 Langman MJS, Morgan L, Worrall A. Use of anti-inflammatory drugs by patients admitted with small or large bowel perforations and haemorrhage. BMF 1985;290:347-9.

30 Bjarnason I, Price AB, Zanelli G, Smethurst P, Burke $M$, Gumpel JM, et al. Clinicopathological features of non-steroidal anti-inflammatory druginduced small intestinal strictures. Gastroenterology 1988;94:1070-4.

31 Bjarnason I, Zanelli G, Smith T, Prouse P, Williams P, Smethurst P, et al. Non-steroidal anti-inflammatory drug induced intestinal inflammation in humans. Gastroenterology 1987;93:480-9.

(Accepted 31 fanuary 1995)

\title{
Case-control study of migraine and risk of ischaemic stroke in young women
}

Christophe Tzourio, Alain Tehindrazanarivelo, Serge Iglésias, Annick Alpérovitch, François Chedru, Jacques d'Anglejan-Chatillon, Marie-Germaine Bousser

\section{Abstract}

Objective-To determine whether migraine is a risk factor for ischaemic stroke in young women.

Design-A case-control study.

Setting-Five hospitals in Paris and suburbs.

Subjects-72 women aged under 45 with ischaemic stroke and 173 controls randomly selected from women hospitalised in the same centres.

Main outcome measures-Ischaemic stroke confirmed by cerebral computerised tomography or magnetic resonance imaging; history of headache recorded with structured interview, and diagnosis of migraine assessed by reproducibility study.

Results-Ischaemic stroke was strongly associated with migraine, both migraine without aura (odds ratio $3.0(95 \%$ confidence interval 1.5 to 5.8$)$ ) and

INSERM U 360,

Recherches

Epidémiologiques en

Neurologie et

Psychopathologie,

Cedex 94807 Villejuif,

France

Christophe Tzourio, clinical epidemiologist

Annick Alpérovitch, director of research

Service de Neurologie, Hôpital Saint-Antoine,

Paris, France

Alain Tehindrazanarivelo, senior registrar

Serge Iglésias, registrar

Marie-Germaine Bousser,

professor of neurology

Service de Neurologie, Hôpital de Meaux, France François Chedru, head of department

Service de Neurologie, Hôpital de Versailles, France

Jacques d'Anglejan-

Chatillon, head of department

Correspondence to:

Dr Tzourio.

$B M 7$ 1995;310:830-3 migraine with aura (odds ratio $6 \cdot 2(2 \cdot 1$ to $18 \cdot 0)$ ). The risk of ischaemic stroke was substantially increased for migrainous women who were using oral contraceptives (odds ratio 13.9) or who were heavy smokers ( $\geqslant 20$ cigarettes/day) (odds ratio 10.2).

Conclusions-These results indicate an independent association between migraine and the risk of ischaemic stroke in young women. Although the absolute risk of ischaemic stroke in young women with migraine is low, the reduction of known risk factors for stroke, in particular smoking and use of oral contraceptives, should be considered in this group.

\section{Introduction}

Few epidemiological studies have investigated the possible association between migraine and stroke. One of the main reasons for this was the lack of precise criteria for the diagnosis of migraine until 1988, when the International Headache Society established operational criteria. ${ }^{1}$ Using these criteria, we found that migraine was not related to ischaemic stroke except in women aged under $45: 65 \%$ of young women with ischaemic stroke had migraine compared with $30 \%$ of controls $(P=0.03) .^{2}$ This result, however, was questionable as it was extracted from a subgroup analysis with only 20 pairs of cases and controls.

The main aim of this study was to investigate the relation between migraine and ischaemic stroke in young women. It was also designed to study the relation between migraine, stroke, and two known vascular risk factors in this group: use of oral contraceptives and cigarette smoking.

\section{Subjects and methods}

We conducted a case-control study, cases being women aged under 45 who were hospitalised for an ischaemic stroke, in five neurological departments from January 1990 to December 1993. Three of the departments were in academic centres in Paris that were already involved in a study including all young patients consecutively admitted for ischaemic stroke. The two others were neurological departments of general hospitals located in small towns near Paris. Patients eligible for inclusion were women aged 18-44 with a diagnosis of first ischaemic stroke (codes 433, 434, and 436 of International Classification of Diseases, ninth revision). All cases were confirmed by cerebral computed tomography or magnetic resonance imaging. Of the 85 eligible patients admitted during the study period, two died after their stroke and one patient with dysphasia was excluded. Of the 82 remaining patients, 10 could not be located despite various efforts. Therefore, 72 patients were contacted and agreed to participate: 40 were hospitalised in the academic centres, and 32 were in the general hospitals. The mean elapsed time between stroke and interview was 19.5 months (SD 12.7)

Cervical ultrasound examination, electrocardiography, and usual laboratory studies were performed on all patients. Most patients underwent further investigations to determine the aetiology of the stroke: cerebral angiography (68), echocardiography (63), transoesophageal echocardiography (56 (92\% of cases without arterial dissection)), transthoracic echocardiography (7), anticardiolipin antibodies (30), and coagulation studies (59). These investigations revealed various abnormalities associated with a higher risk of stroke: arterial dissection (22), carotid occlusion of unknown cause (5), carotid atheroma (5), anticardiolipin antibodies (6), essential thrombocytaemia (1), paroxysmal atrial fibrillation (1), mitral valve stenosis (2), patent foramen ovale (11), and atrial septal aneurysm (11). This last abnormality was diagnosed with transoesophageal echocardiography when the atrial septum presented an excursion of more than $6 \mathrm{~mm}$ in the right or left atrium. None of the patients was pregnant at the time of the stroke.

Controls were women randomly selected from 
patients hospitalised in the same centres during the same period for acute orthopaedic or benign rheumatological illnesses. Altogether, 225 women aged under 45 were asked by mail to participate in an epidemiological study and to send their written consent to a telephone interview; 188 responded, of which 15 refused to participate. Thus, $173(77 \%)$ agreed to participate and were enrolled in the study: 64 had been hospitalised for traumatic orthopaedic injuries, 49 for benign orthopaedic operations (arthroscopy, carpal tunnel decompression, removal of surgical material, or removal of sebaceous cysts), 44 for recent severe low back pain, eight for localised infections, and eight for miscellaneous procedures. None was receiving long term (above three months) treatment with analgesic or anti-inflammatory drugs that could have altered their answers concerning migraine. None had a history of stroke.

All cases and controls were interviewed by telephone about their history of headaches and their vascular risk factors. For cases, exposure to risk factors only at the time of their stroke was considered; in particular, history of headache only before the stroke was recorded. The questionnaire covered patients' history of hypertension, diabetes, cigarette smoking, use of oral contraceptives, hypercholesterolaemia, weight, height, and educational background. Smoking was defined as having smoked more than five cigarettes daily for at least a year. Current smokers were still smoking at the time of the stroke or had ceased less than one month before, whereas former smokers had given up more than one month before the stroke. The same definitions of former and present users were applied to taking oral contraceptives. All interviews were conducted by one of three neurologists with expertise in headaches (CT, AT, and SI). They used a highly structured questionnaire, including 23 different questions on headache based on the International Headache Society's criteria, ${ }^{12}$ and from which the diagnosis of migraine could be easily derived. The subjects were not aware of the aim of the study: they were just asked if they agreed to take part in an epidemiological study on health matters.

\section{STATISTICAL ANALYSIS}

Categorical variables were compared with Pearson's $\chi^{2}$ test and, when necessary, Fisher's two-tailed test of exact probability. Continuous variables were compared with two-tailed $t$ tests for comparisons of means. Because the incidence of stroke is low in the general population, odds ratios were used as a close approximation to relative risk; they were calculated by stepwise unconditional multiple logistic regression. ${ }^{3}$ Hypothesis testing and estimation of $95 \%$ confidence intervals were carried out with the standard error estimate for the logistic coefficient estimates. Unconditional logistic regression was used to assess the interaction between migraine and use of oral contraceptive or smoking. Data were analysed with SAs. ${ }^{+}$

Estimation of absolute risk-As there was no direct method for estimating the absolute risk of stroke associated with migraine from our data, we used the following procedure. We assumed that the mean incidence of ischaemic stroke in young women was 10 in 100000 woman years. ${ }^{56}$ The 72 cases of this study were thus drawn from a theoretical population of 720000 person years. We also assumed that the controls constituted a representative sample of this population. ${ }^{3}$ Then, if $\mathrm{p}$ is the prevalence of migraine in the controls, the absolute risk of stroke is $n_{1} /(720000 \times$ $p)$ in women with migraine and $n_{2} /(720000 \times(1-p))$ in women without migraine, $n_{1}$ and $n_{2}$ being the number of cases with and without migraine respectively.

Reproducibility study-Interobserver agreement was calculated for the reproducibility of the diagnosis of migraine. Sixty women ( 30 cases and 30 controls) had a replicate telephone interview by another neurologist five to nine months after their first interview. They were chosen randomly from the lists of cases and controls and were asked by telephone to participate in a complementary study. All 60 women agreed to participate. Case patients were instructed not to talk about their stroke during the interview. Then each call was transferred to a neurologist blinded to the status (case or control) of the patient. In this second interview only questions about headaches were asked in order to keep the observer blinded. The $\kappa$ index was used to evaluate the interobserver variability. ${ }^{7}$ The global $k$ index for the 60 women was $0 \cdot 83$. For the cases, the observers disagreed about three women; two who were initially thought to have migraine and one thought to be without. Therefore the $\kappa$ index in cases was 0.79 . for the 30 controls, there was disagreement about two women, one with an initial diagnosis of migraine and one without, yielding a $\kappa$ index of $0 \cdot 83$.

Bias due to non-response in controls-Non-response in controls $(23 \%)$ could be an important issue in this study because the willingness to participate in the telephone interview could depend on the patient's migraine status. Therefore, another study was carried out to obtain another estimate of the prevalence of migraine in controls. Comparison between this figure and the observed prevalence of migraine in controls was used to evaluate the possible bias due to nonresponse in controls. An extra 57 women aged under 45 were visited by the same neurologists during their hospitalisation in an orthopaedic department. The interviewers asked the women if they would participate in an epidemiological study about their health status, and, as expected, all accepted. These women had the same demographic characteristics and a similar exposure to the main vascular risk factors as the controls. Eighteen $(32 \%)$ of them had migraine, and this figure was considered to be a fair estimate of the expected prevalence of migraine in controls.

\section{Results}

Table I shows the baseline characteristics of the patients with stroke and the controls. No difference was found between the cases and controls in their mean age, body mass index, history of diabetes, and educational background. However, the two groups

TABLE I-Baseline characteristics of young women who had ischaemic stroke and of controls. Values are numbers (percentages) unless stated otherwise

\begin{tabular}{|c|c|c|c|}
\hline & $\begin{array}{l}\text { Stroke } \\
\text { patients } \\
(\mathrm{n}=72)\end{array}$ & $\begin{array}{l}\text { Controls } \\
(n=173)\end{array}$ & P value \\
\hline Mean (SD) age ${ }^{\star}$ & $35 \cdot 7(7 \cdot 4)$ & $35 \cdot 1(7 \cdot 5)$ & 0.678 \\
\hline Mean (SD) body mass index $\left(\mathrm{kg} / \mathrm{m}^{2}\right)$ & $22 \cdot 4(4 \cdot 3)$ & $22.9(3.9)$ & $0 \cdot 348$ \\
\hline History of hypertension & $14(19)$ & $12(11)$ & 0.077 \\
\hline History of hypercholesterolaemia & $16(22)$ & $15(9)$ & 0.003 \\
\hline History of diabetes & $1(1)$ & $1(1)$ & $0 \cdot 521$ \\
\hline \multicolumn{4}{|l|}{ Cigarette smoking: } \\
\hline Never & $25(35)$ & $82(47)$ & \multirow{4}{*}{$0.043+$} \\
\hline Former & $15(21)$ & $28(16)$ & \\
\hline Current low ( $<20$ cigarettes/day) & $9(13)$ & $32(18)$ & \\
\hline Current high ( $\geqslant 20$ cigarettes/day) & $23(32)$ & $31(18)$ & \\
\hline \multicolumn{4}{|l|}{ Use of oral contraceptives: } \\
\hline Never & $6(8)$ & $25(14)$ & \multirow{3}{*}{$<0.001 \dagger$} \\
\hline Former & $19(26)$ & $85(49)$ & \\
\hline Current & $47(65)$ & $63(36)$ & \\
\hline \multicolumn{4}{|c|}{ Hormonal content of oral contraceptives $\ddagger$ : } \\
\hline Progestogen only & $1 / 41(2)$ & $4 / 62(6)$ & \multirow{4}{*}{$0.506 t$} \\
\hline $20 \mu \mathrm{g}$ oestrogen & $2 / 41(5)$ & $5 / 62(8)$ & \\
\hline $30-40 \mu \mathrm{g}$ oestrogen & $30 / 41(73)$ & $46 / 62(74)$ & \\
\hline $50 \mu \mathrm{g}$ oestrogen & $8 / 41(20)$ & $7 / 62(11)$ & \\
\hline \multicolumn{4}{|l|}{ Education: } \\
\hline Primary school or less & $12(17)$ & $18(10)$ & \multirow{4}{*}{$0.498 t$} \\
\hline Secondary school (short cycle) & $22(31)$ & $49(28)$ & \\
\hline Secondary school (long cycle) & $19(26)$ & $55(32)$ & \\
\hline Higher education or university & $19(26)$ & $51(29)$ & \\
\hline
\end{tabular}

${ }^{\star}$ Age at the time of stroke for cases, age at the time of interview for controls. †Pearson's $\chi^{2}$ test

fCurrent users of contraceptives only. 
differed according to use of oral contraceptives, smoking, history of hypercholesterolaemia, and history of hypertension. The risk associated with using oral contraceptives was mainly due to current use (odds ratio $3 \cdot 1(95 \%$ confidence interval $1 \cdot 2$ to $8 \cdot 2))$. In current users risk of stroke was related to dose of oestrogen: the odds ratio was 4.8 for pills containing $50 \mu \mathrm{g}$ oestrogen, $2 \cdot 7$ for pills containing $30-40 \mu \mathrm{g}, 1 \cdot 7$ for pills containing $20 \mu \mathrm{g}$, and 1.0 for pills containing progestogen. In the last two categories, however, the numbers were small. Among smokers, only current heavy smokers ( $\geqslant 20$ cigarettes/day) were at significantly higher risk of ischaemic stroke (odds ratio $2 \cdot 4(1 \cdot 2$ to $4 \cdot 9)$ ). No association was found between migraine and present use of oral contraceptives in cases $(P=0.59)$ and controls $(P=0.31)$ or between migraine and smoking in cases $(P=0.84)$ and controls $(P=0.37)$.

Table II shows that migraine and ischaemic stroke were strongly associated; $60 \%$ (95\% confidence interval $48 \%$ to $71 \%$ ) of cases had migraine compared with $30 \%$ $(23 \%$ to $37 \%)$ of controls $(\mathrm{P}<0.001)$. This association persisted after we controlled for age, history of hypertension, use of oral contraceptives, and smoking. Women with migraine had a more than threefold increased risk of ischaemic stroke compared with women without migraine. This increase occurred with both types of migraine, although the risk was higher with migraine with aura (odds ratio 6.2) than with migraine without aura (odds ratio $3 \cdot 0$ ). With the assumption of an incidence of ischaemic stroke in young women of 10 in 100000 woman years, the absolute risk of ischaemic stroke would be 6 per 100000 women per year for women without migraine and 19 per 100000 per year for women with migraine.

TABLE II-Occurrence of migraine in young women who had ischaemic stroke and in controls. Values are numbers (percentages)

\begin{tabular}{|c|c|c|c|c|}
\hline & $\begin{array}{l}\text { Stroke } \\
\text { patients } \\
(\mathrm{n}=72)\end{array}$ & $\begin{array}{l}\text { Controls } \\
(n=173)\end{array}$ & $\begin{array}{l}\text { Adjusted odds } \\
\text { ratio } \\
(95 \% \text { confidence } \\
\text { interval })^{\star}\end{array}$ & Pvalue \\
\hline Without migraine $\dagger$ & $29(40)$ & $121(70)$ & 1 & - \\
\hline With migraine: & $43(60)$ & $52(30)$ & $3.5(1.8$ to 6.4$)$ & $<0.001$ \\
\hline Migraine without aura & $33(46)$ & $42(24)$ & $3.0(1.5$ to 5.8$)$ & $<0.001$ \\
\hline Migraine with aura & $10(14)$ & $10(6)$ & $6 \cdot 2(2 \cdot 1$ to $18 \cdot 0)$ & $<0.001$ \\
\hline
\end{tabular}

${ }^{\star}$ Calculated by unconditional logistic regression controlling for age, tobacco smoking, history of hypertension, and use of oral contraceptives. †Reference category.

Table III shows relation between risk of ischaemic stroke and migraine, using oral contraceptives, and smoking. The risk of stroke in migrainous women using oral contraceptives was 13.9 compared with those without migraine not using oral contraceptives $(P<0.001)$. There was no evidence of a statistical interaction between migraine and the use of oral contraceptives. Of the women who used oral contraceptives, those who had migraine still had a fourfold increased risk of ischaemic stroke. With regard to the risk of stroke in migrainous patients who smoked, we decided to focus on current heavy smokers, who were at a higher risk of ischaemic stroke (table I). The odds ratio of stroke in migrainous women who smoked

TABLE III-Risk of ischaemic stroke in young women by having migraine, using oral contraceptives, and smoking. Values are odds ratios (95\% confidence intervals)

\begin{tabular}{|c|c|c|}
\hline & $\begin{array}{l}\text { Women without } \\
\text { migraine }\end{array}$ & $\begin{array}{l}\text { Women with } \\
\text { migraine }\end{array}$ \\
\hline \multicolumn{3}{|l|}{ Use of oral contraceptives: } \\
\hline No & $1^{\star}$ & $3.7(1.5$ to $9 \cdot 1)$ \\
\hline Yes† & $3.5(1.5$ to 8.3$)$ & $13.9(5.5$ to 35.1$)$ \\
\hline \multicolumn{3}{|l|}{ Heavy smoking ( $\geqslant 20$ cigarettes/day): } \\
\hline No & $1^{\star}$ & $5 \cdot 8(2 \cdot 2$ to $15 \cdot 3)$ \\
\hline Yes & $3.0(1.0$ to 9.0$)$ & $10.2(3.5$ to 29.9$)$ \\
\hline
\end{tabular}

heavily was $10 \cdot 2$ compared with women without migraine who never smoked $(P<0.001)$. Again, no statistical interaction could be found between migraine and tobacco consumption. Among current heavy smokers, migraine increased the risk of ischaemic stroke by a factor of $3 \cdot 4$.

Concerning the aetiology of stroke, we observed no migrainous infarct (defined according to the International Headache Society classification): five women with migraine with aura had headaches preceding or accompanying their stroke, but the neurological deficit was not similar to the aura symptoms.' Three of the patients with migraine were receiving prophylactic treatment at the time of their stroke: one received dihydroergotamine, one a $\beta$ blocking drug, and one pizotifen. Only one woman took a vasoactive drug (ergotamine tartrate) just before the stroke. Prevalence of migraine was similar in patients with arterial lesions $(63 \%)$, cardiac abnormalities (76\%), and systemic disorders $(57 \%)$.

\section{Discussion}

In this study we found migraine to be strongly associated with ischaemic stroke in young women independently of the main vascular risk factors (adjusted odds ratio 3.5). The risk of ischaemic stroke was particularly increased for migrainous women who were currently using oral contraceptives (odds ratio 13.9) or were current heavy smokers (odds ratio 10.2).

In other controlled studies migraine was generally not found to be a risk factor for ischaemic stroke, except for migraine with aura ${ }^{89}$ or with certain subgroups of patients. ${ }^{210}$ However, few studies have specifically addressed this issue, and the association between migraine and ischaemic stroke in young women in particular was evaluated only by the Collaborative Group for the Study of Stroke in Young Women. ${ }^{10}$ In that study migraine was found in $34 \%$ of cases, $24 \%$ of neighbourhood controls (odds ratio $1 \cdot 7$ ), and $33 \%$ of hospitalised controls (odds ratio $1 \cdot 1)$. These figures of migraine prevalence are much lower than those in our study. Apart from methodological limitations, ${ }^{211}$ one of the possible explanations for this discrepancy is the difference in methods and criteria used for the diagnosis of migraine. In our study history of headache was collected by trained neurologists using a structured questionnaire and the diagnosis of migraine was based on the International Headache Society criteria. These criteria, though precise and complex, often indicate a high prevalence of migraine in young women: in recent studies in the general population the prevalence of migraine in young women was close to $30 \%$, the same figure obtained in our controls. ${ }^{1213}$

\section{POTENTIAL BIAS}

The high prevalence of migraine in stroke sufferers could be due to biases such as selection bias, classification bias regarding the diagnosis of migraine, or information bias including recall bias. It seems unlikely that cases would have been selected in this study because of their migraine, since most of our cases were part of a consecutive series of young patients with stroke. A referral bias in academic centres is also unlikely since the prevalence of migraine was similar in both academic and non-academic centres $(60 \%$ and $63 \%$ respectively). Concerning non-responders among cases, it was verified that, even if the 10 women not contacted did not have migraine, the association between migraine and ischaemic stroke would still be significant (data not shown).

A classification bias could have occurred since the observers were aware of the clinical status of the patients, but a structured questionnaire was used in 
order to overcome this potential bias. Furthermore, in the reproducibility study, when the investigators were unaware of the patients' clinical status, interobserver agreement was good in cases $(\kappa$ index $=0.79$ ) and controls. Because about half of the cases participated in the reproducibility study and were randomly selected, it is unlikely that the high prevalence of migraine observed in cases could be due to misclassification. Recall bias is possible because cases suffering from a brain disease might have been more prone than controls to remember their headache. This cannot be ruled out, but it is unlikely with a chronic and recurrent condition such as migraine. ${ }^{2}$

Controls were selected among patients admitted in the same hospitals as the cases in order to obtain groups that were broadly similar with regard to area of residence and socioeconomic status. This similarity was retrospectively verified since the educational background was similar in both groups. Regarding nonresponse in controls $(23 \%)$, the complementary study among hospitalised women-in which all those invited agreed to participate-found a prevalence of migraine very similar to that observed in our control patients. The controls who did not participate were therefore unlikely to be a selection of migrainous women.

Finally, the association between migraine and ischaemic stroke was so strong that it is highly unlikely that it could be totally explained by any of the biases mentioned above, even in combination.

\section{IMPLICATIONS}

The strength of the association should not, however, lead to the conclusion that all young women with migraine are at high risk of stroke. Under the assumption of an incidence of ischaemic stroke in young women of 10 in 100000 woman years, we calculated that the absolute risk of ischaemic stroke would be only 19 per 100000 women with migraine per year. Furthermore, it is not known whether this increased risk relates to all young migrainous women or only a subgroup of them. Migraine could be part of another physiopathogenic process-such as MELAS syndrome $e^{14}$ or antiphospholipid antibodies syndrome ${ }^{15}$ - that leads to ischaemic stroke. Such migraine, probably more appropriately called migraine-like headache, would then be considered only as a marker of this process. These conditions are rare and were not found in our study, but other unknown mechanisms of this kind could exist. An important area of future research would be to try to define a subgroup of young women with migraine at highly increased risk of stroke.

Also, migraine could be an important risk factor only in women with a condition predisposing to ischaemic stroke, such as a patent foramen ovale or an atrial septal aneurysm. ${ }^{16}{ }^{17}$ The platelet hyperaggregability described by some authors during migraine ${ }^{18-20}$ could greatly increase the risk of embolic stroke in women with these cardiac abnormalities. Migraine would then be acting as a cofactor in the process leading to stroke. We could not test this hypothesis because our controls did not undergo the same investigations as the cases.

As long as the mechanisms explaining the association between migraine and ischaemic stroke in young women remain unclear and since potentially predisposing conditions could not be routinely checked in all young women with migraine, the practical implications of this association are limited. However, on the strength of our results we suggest that

\section{Key points}

- Previous studies have suggested a possible association between migraine and ischaemic stroke in young women

- In this study there was an independent association between migraine and stroke in women aged under 45

- The risk of ischaemic stroke was higher among young women with migraine who smoked or who took oral contraceptives

- Although their absolute risk of ischaemic stroke is still low, young women with migraine should be advised not to smoke and, if they use oral contraceptives, to choose low dose pills

young women should be advised not to smoke and, if they use oral contraceptives, to choose pills with a low dose of oestrogen since these carry a smaller risk of stroke. ${ }^{21}$

This work was supported by a research grant from GLAXO France. We thank the participants of the AICSJ study for allowing us to include their patients; Philipp Armstrong and Monique Breteler for helpful comments on the manuscript; and the patients who voluntarily participated in this study.

1 Headache Classification Committee of the International Headache Society. Classification and diagnostic criteria for headache disorders, cranial neuralgias and facial pain. Cephalalgia 1988;8(supp 7):1-96.

2 Tzourio C, Iglesias $S$, Hubert J-B, Visy J-M, Alperovitch A, Tehindrazanarivelo A, et al. Migraine and risk of ischaemic stroke: a case-control study. $B M \mathcal{F}$ 1993;308:289-92.

3 Breslow NE, Day NE. Statistical methods in cancer research. Vol 1. The analysis of case-control studies. Lyons: International Agency for Research on Cancer. 1980.

4 SAS Institute. SAS user's guide: statistics. Version 6. Vol 1. Cary, NC: SAS Institute, 1990.

5 Schoenberg BS, Whisnant JP, Taylor WF, Kempers RD. Strokes in women of childbearing age. A population study. Neurology (NY) 1970;20:181-9.

6 Lidegaard $O$. Cerebrovascular deaths before and after the appearance of oral contraceptives. Acta Neurol Scand 1987;75:427-33.

7 Fleiss JL. Statistical methods for rates and proportions. 2nd ed. New York: Wiley, 1981

8 Henrich JB, Horwitz RI. A controlled study of ischaemic stroke risk in migraine patients. 9 Clin Epidemiol 1989;42:773-80.

9 Marini C, Carolei A, Roberts RS, Prencipe M, Gandolfo C, Inzitari D, et al. Focal cerebral ischemia in young adults: a collaborative case-control study. Neuroepidemiology 1993;12:70-81.

10 Collaborative Group for the Study of Stroke in Young Women. Oral contraceptives and stroke in young women. Associated risk factors. FAMA 1975;231:718-22.

11 Tatemichi TK, Mohr JP. Migraine and stroke: In: Barnett HJM, Mohr JP, Stein BM, Yatsu FM, eds. Stroke: pathophysiology, diagnosis and management. 2nd ed. New York: Churchill Livingstone, 1992:761-85.

12 Rasmussen BK, Jensen R, Schroll M, Olesen J. Epidemiology of headache in a general population. A prevalence study. $\mathcal{F}$ Clin Epidemiol 1991;11:1147-57.

13 Henry P, Michel P, Brochet B, Dartigues JF, Tison S, Salamon R. GRIM: a nationwide survey of migraine in France. Prevalence and clinical features in adults. Cephalalgia 1992;12:229-37.

14 Montagna P, Galassi R, Medori R, Govoni E, Zeviani M, Di Mauro S, et al. MELAS syndrome: characteristic migrainous and epileptic features and maternal transmission. Neurology 1988;38:751-4.

15. Levine SR, Welch KMA. Antiphospholipid antibodies. Ann Neurol 1989;26: 386-9.

16 Lechat P, Mas JL, Lascault G, Loron P, Theard M, Klimczac M, et al. Prevalence of patent foramen ovale in patients with stroke. $N \mathrm{Engl} f \mathrm{Med}$ 1988;318:1148-52.

17 Pearson AC, Nagelhout D, Castello R, Gomez C, Labovitz A. Atrial septal aneurysm and stroke: a transesophageal echocardiographic study. $f \mathrm{Am}$ Coll Cardiol 1991;18:1223-9.

18 Couch JR, Hassanein RS. Platelet aggregability in migraine. Neurology 1977:27:843-8.

19 Kalendovsky Z, Austin J, Steele P. Increased platelet aggregability in young patients with stroke. Arch Neurol 1975;32:13-20.

20 Gawel MJ, Rose FC. Platelet function in migraineurs. Adv Neurol 1982;33: 237-42.

21 Lidegaard $O$. Oral contraception and the risk of a cerebral thromboembolic attack: results of a case-control study. BMf 1993;306:956-63.

(Accepted 31 fanuary 1995) 